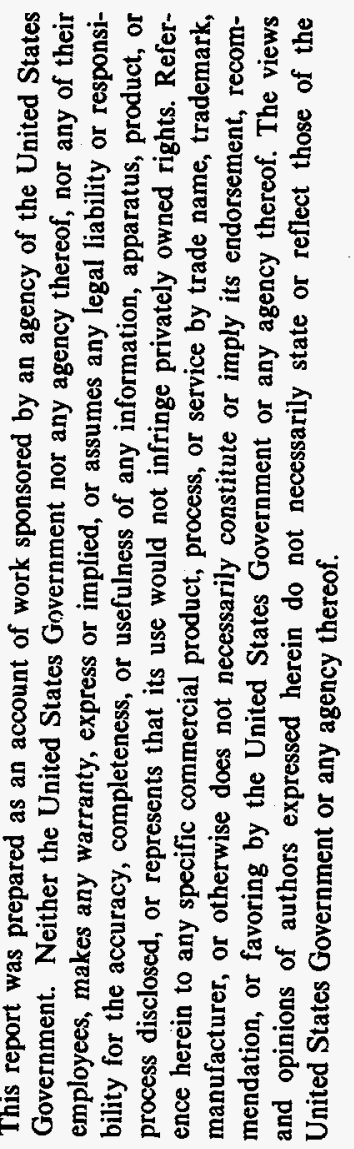

\title{
HEATPIPE SPACE POWER AND PROPULSION SYSTEMS
}

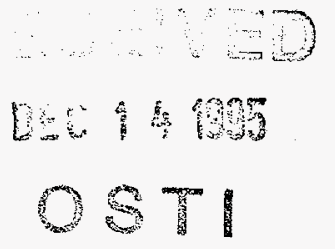

\author{
MICHAEL G. HOUTS \\ DAVID I. POSTON \\ WILLIAM A. RANKEN
}

Submitted to:

\section{STAIF-96 MEETING, JANUARY 7-11, 1996, ALBUQUERQUE, NM}

\section{Los Alamos}

NATIONAL LABORATORY

DISTRIBUTION OF THIS DOCUMENT IS UNLIMITED

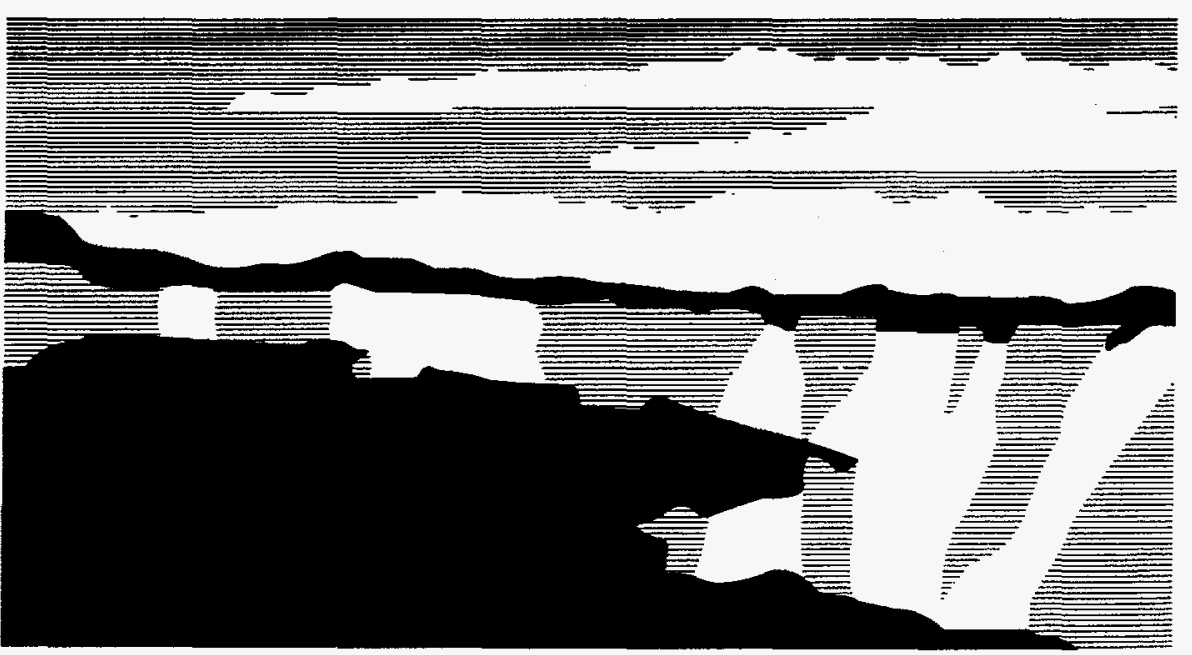

Los Alamos National Laboratory, an aftirmative action/equal opportunity empldyer, is operated by the University of California for the U.S. Department of Energy under contract W-7405-ENG-36. By acceptance of this article, the publisher recognizes that the U.S. Government retains a nonexclusive, royalfy-free license to publish or reproduce the published form of this contribution, or to altow others to do so, for U.S. Government purposes. The Los Alamos National Laboratory requests that the publisher identify this anticle as work performed under the auspices of the U.S. Department of Energy. 


\section{DISCLAMMER}

Portions of this document may be illegible in electronic image products. Images are produced from the best available original document. 


\title{
HEATPIPE SPACE POWER AND PROPULSION SYSTEMS
}

\author{
Michael G. Houts, David I. Poston, and William A. Ranken \\ Los Alamos National Laboratory, MS K551 \\ Los Alamos, NM 87545 \\ (505)665-4336/(505)665-3167 (FAX)
}

\begin{abstract}
Safe, reliable, low-mass space power and propulsion systems could have numerous civilian and military applications. This paper discusses two fission-powered concepts: the Heatpipe Power System (HPS), which provides power only; and the Heatpipe Bimodal System (HBS), which provides both power and thermal propulsion. Both concepts have 10 important features. First, only existing technology and recently tested fuel forms are used. Second, fuel can be removed whenever desired, which greatly facilitates system fabrication and handling. Third, full electrically heated system testing of all modes is possible, with minimal operations required to replace the heaters with fuel and to ready the system for launch. Fourth, the systems are passively subcritical during launch accidents. Fifth, a modular approach is used, and most technical issues can be resolved with inexpensive module tests. Sixth, bonds between dissimilar metals are minimized. Seventh, there are no single-point failures during power mode operation. Eighth, the fuel burnup rate is quite low to help ensure $>10-y \mathrm{r}$ system life. Ninth, there are no pumped coolant loops, and the systems can be shut down and restarted without coolant freeze/thaw concerns. Finally, full ground nuclear test is not needed, and development costs will be low. One design for a low-power HPS uses SNAP$10 \mathrm{~A}$-style thermoelectric power converters to produce $5 \mathrm{kWe}$ at a system mass of $\sim 500 \mathrm{~kg}$. The unicouple thermoelectric converters have a hot-shoe temperature of $1275 \mathrm{~K}$ and reject waste heat at $775 \mathrm{~K}$. This type of thermoelectric converter has been used extensively by the space program and has demonstrated an operational lifetime of decades. A core with a larger number of smaller modules (same overall size) can be used to provide up to 500 $\mathrm{kWt}$ to a power conversion subsystem, and a slightly larger core using a higher heatpipe to fuel ratio can provide $>1$ MWt. The baseline HBS produces $>50 \mathrm{~N}$ of thrust at a specific impulse $>750 \mathrm{~s}$, can operate for long periods of time (hundreds of hours, limited by propellant supply) in bimodal mode, produces $>5 \mathrm{kWe}$ in power or bimodal mode, has $>10-\mathrm{yr}$ power mode life, and has a mass of $\sim 800 \mathrm{~kg}$. HPS development cost (through flight unit fabrication, thermal testing, and zero-power nuclear testing) should be less than $\$ 100 \mathrm{M}$. The HBS development cost will be higher than HPS development cost because of the added complexity of the bimodal system.
\end{abstract}

\section{INTRODUCTION}

Safe, reliable, low-mass space power and propulsion systems could have numerous civilian and military applications. Fission systems have the following potential advantages.

1. Cost. Once developed, the unit cost of a fission system can be less than that for competing systems (solar and isotopic).

2. Scalability. Fission systems are capable of producing extremely high power.

3. Operating environment. Fission systems operate independently of solar proximity or orientation and are well suited for missions to Mars and beyond. Fission systems can tolerate high-radiation fields and can be designed to operate in dusty environments. Fission systems also are well suited for surface operations where solar energy may not always be available.

4. Launch approval. Fission systems contain no plutonium and are nonradioactive at launch, which may facilitate launch approval.

The most common disadvantages associated with fission systems are nontechnical in nature. One is the perception that fission systems will cost billions of dollars to develop. This paper proposes two concepts that through using existing facilities and technology developed over the last $40 \mathrm{yr}$ should have development costs of $\sim \$ 100 \mathrm{M}$. Another issue that has curtailed the development of space fission systems is the large number of regulations that deal with nuclear systems. The systems proposed in this paper have two characteristics that should minimize regulatory 
delays: there is no requirement for a nuclear ground test; and the systems can be tested, assembled, and transported separately from the nuclear fuel. One additional issue is the negative attitude toward nuclear systems among some members of the public and user community. The driving factors behind the design of the Heatpipe Power System (HPS) and Heatpipe Bimodal System (HBS) are simplicity and safety. This will help gain acceptance early in the program and, more importantly, keep failures from occurring.

\section{HEATPIPE POWER SYSTEM}

The HPS uses similar (or identical) modules to create a core with the performance and lifetime required for a given mission. A wide variety of core layouts has been evaluated, with the number of modules ranging from 12 to $>100$. A schematic of the 12-module HPS is shown in Fig. 1, and a schematic of a four fuel-pin HPS module is given in Fig. 2. The fuel pins are bonded structurally and thermally to a central heatpipe, which transfers heat to an ex-core power conversion system. The heatpipe also provides structural support for the fuel pins. Modules are independent during normal operation. If a heatpipe fails, some thermal bonding between modules is desirable to reduce peak temperatures. Thermal radiation provides some thermal bonding, which can be enhanced by adding helium or lithium to the interstitial spaces, by brazing modules to adjacent modules, or by adding refractory metal wool to the interstitial spaces. Three fuel types have been evaluated for use in the HPS: uranium nitride (UN), uranium dioxide $\left(\mathrm{UO}_{2}\right)$, and uranium carbonitride (UCN). The use of uranium nitride results in the most compact core. However, uranium nitride fuel pins must be sealed hermetically, and the peak fuel temperature should be limited to $-1800 \mathrm{~K}$ (Matthews 1994). Uranium dioxide has a lower uranium loading than uranium nitride, but the pins do not have to be sealed hermetically and can run at a higher temperature than uranium nitride pins. Uranium carbonitride has a high uranium loading, does not have to be sealed hermetically, and can operate at a high temperature. However, most data on uranium carbonitride fuel resides in Russia, and there is little US experience.

The HPS primary heatpipes operate at a temperature of $\sim 1300 \mathrm{~K}$ and transfer heat to secondary heatpipes operating at $-1275 \mathrm{~K}$. Heat is transferred from the secondary heatpipes to the thermal to electric power converters, and waste heat is rejected to space. The $1275 \mathrm{~K}$ converter hot-side temperature is adequate for many types of power conversion, although higher or lower temperatures could be used. One option for HPS power conversion (especially at relatively low power) is thermoelectric power conversion. Unicouple thermoelectric converters that are well suited for use with HPS have been designed (Raag 1995). These converters have a hot-shoe temperature of $1275 \mathrm{~K}$ and reject waste heat at $775 \mathrm{~K}$. This general type of thermoelectric converter has been used extensively by the space program and has demonstrated an operational lifetime of decades (Ranken et al. 1990).

An HPS has been proposed that makes maximum use of existing hardware and facilities. This version of HPS uses 12 modules, each containing 4 rhenium-lined, $\mathrm{Nb}-1 \mathrm{Zr}$-clad uranium nitride fuel pins bonded to a central heatpipe. The fuel pin's outer diameter is $2.54 \mathrm{~cm}$, which allows existing electrical heaters to be used for testing (Izhvanov 1995). Fabrication cost for the first module, including the central heatpipe, is $\sim \$ 100 \mathrm{k}$. The use of existing electrical heaters reduces the cost of an electrically heated module test-different module sizes can be tested if an additional $\$ 40 \mathrm{k}$ is available for new heaters.

The HPS has a low fuel-burnup rate, and no fuel development program is required. In the SP-100 program, uranium nitride fuel in a very similar configuration was tested to the equivalent burnup of several decades of lifetime (Makenas et al. 1994). Uranium dioxide or uranium carbonitride fuel also can be used, although system mass would increase because of the lower uranium density. The life-limiting feature in the baseline HPS may be the thermoelectric power converters, although they also have long-life potential. Fuel can be removed from the HPS whenever desired, which would facilitate fabrication and handling greatly. The HPS is inherently subcritical during launch accidents and has no single-point failures. The HPS can undergo full electrically heated system testing at existing facilities. Each of the HPS modules is independent, allowing most technical issues to be resolved with inexpensive module tests.

Mechanical bonding within the HPS modules is achieved by methods such as a tack weld, an electron beam weld, chemical vapor infiltration $(\mathrm{CVI})$, or hot isostatic pressing. For low-power cores $(<100 \mathrm{kWt})$, radiation heat transfer will be adequate if finned (or small) heatpipes are used and if some reduction in power is acceptable following the loss of a heatpipe. If some thermal bonding is desired, it can be accomplished by methods such as an electron beam weld, a braze, a helium bond, the use of a refractory metal wool, or CVI. During power operation, there will be some asymmetry in the fuel radial temperature profile because heat primarily is removed from one section of the fuel clad. However, the temperature asymmetry will not be severe because of the low power density. 
Heat generated in the fuel is transferred to the module heatpipe, which transfers heat to the secondary heatpipes, with the junction located on the surface of the shield. In the thermoelectric option, heat from the secondary heatpipes is transferred to thermoelectric converters that are bonded to the heatpipe surface. Excess heat is rejected radiatively to space from the cold side of the thermoelectrics.

Structural support of the core is provided by the module heatpipes, which are anchored to a molybdenum or $\mathrm{Nb} / 1 \mathrm{Zr}$ tie plate. The pins are confined laterally on the opposite end of the core but are allowed to move freely in the longitudinal direction to allow for differential expansion. Neutron shielding is provided by a lithium hydride shield, and tungsten gamma shielding may or may not be required, depending on the thermal power level, payload separation, and allowable dose. The reference shield assumes an operating power of $100 \mathrm{kWt}$, an allowable gamma dose rate of $5 \times 10^{4} \mathrm{rad} / \mathrm{yr}$, and a neutron dose rate of $10^{12} \mathrm{n} / \mathrm{cm}^{2} / \mathrm{yr}$ (1 MeV equivalent) at a 2.0-m-diameter dose plane located $10 \mathrm{~m}$ from the core's center line. The low dose rate will enable the use of less-expensive components on some missions.

The HPS is designed to remain subcritical during all credible launch accidents. This has been accomplished by keeping the system radius small, keeping the reflector worth high, and strategically placing neutron absorbers in the core. The negative reactivity worth of the control drums in the reflector, or the negative reactivity effect of losing the reflector and surrounding the reactor with wet sand or water, offsets the positive reactivity effect of core flooding or compaction, thus eliminating the need for in-core safety rods. For deep space or planetary surface missions where reentry after reactor startup is impossible, passive launch safety can be obtained by fueling the reactor in space or by using retractable boron wires to provide shutdown. This allows the removal of resonance absorbers from the core and reduces system mass and volume.

HPS scales to $500 \mathrm{kWt}$ with no increase in system mass. Above $500 \mathrm{kWt}$ the system is no longer criticalitylimited, and the heatpipe to fuel ratio must be increased. A $1000 \mathrm{kWt}$ HPS would have a reactor mass slightly higher than that of a $500 \mathrm{kWt}$ system. The $1000 \mathrm{kWt}$ HPS could provide $50 \mathrm{kWe}$, assuming that $5 \%$ efficient power conversion is available.

\section{HEATPIPE BIMODAL SYSTEM}

The HBS has the same features as the HPS and also can heat flowing hydrogen to produce a thrust $>50 \mathrm{~N}$ at a specific impulse $>750 \mathrm{~s}$. The baseline HBS uses tungsten-clad $\mathrm{UO}_{2}$ fuel in a configuration very similar to that used by the Russian TOPAZ II. A vacuum gap separates the HBS heatpipe from the hydrogen flow passages, thus protecting the heatpipe from dryout and hydrogen ingress. As with the HPS, heatpipes transfer heat from the HBS core and provide $>100 \mathrm{kWt}$ at $1275 \mathrm{~K}$ to a power conversion subsystem.

A schematic of the HBS module is shown in Fig. 3. The uranium dioxide pins are quite similar to those tested under the TOPAZ II program (Wold et al. 1994). Extensive experience with tungsten-clad uranium dioxide also has been gained under the Thermionic Fuel Element Verification Program (Houts 1994) and previous programs. Cold hydrogen enters a plenum at the base of the core, then makes a single pass through the interstitial spaces between the fuel pins before exiting through a nozzle. Detailed thermal hydraulic calculations show that the hydrogen is heated to within $25 \mathrm{~K}$ of the adjacent clad temperature in the hot end of the core and that flow channels can be tailored to allow hydrogen outlet temperature to be very close to peak clad temperature.

There is one heatpipe per module in the HBS. The tungsten fuel clad is bonded to a tungsten tube that surrounds a molybdenum heatpipe. The tungsten tube is coupled radiatively to the molybdenum heatpipe. During propulsion, the heat flux seen by the heatpipe is roughly equivalent to that seen during power mode, and the vacuum gap between the tungsten and molybdenum walls reduces hydrogen permeation into the heatpipe. During power operation, there will be some asymmetry in the fuel radial temperature profile because heat primarily is removed from one section of the fuel clad. However, the temperature asymmetry will not be severe because of the low power density. In the combined power and propulsion mode, heat removal from the fuel will be nearly symmetric because of the hydrogen propellant.

The HBS electric power generation capability is slightly less then that of the HPS because of additional heat transfer barriers between the fuel and heatpipe. For high power systems, some additional thermal bonding between 
the tungsten tube and the molybdenum heatpipe may be required. During bimodal operation, the HBS can produce specific impulses up to $800 \mathrm{~s}$ and thrust levels up to a few hundred Newtons. Above a few hundred $\mathrm{N}$ of thrust, peak uranium dioxide temperature is a concern. A high-thrust HBS could be feasible if the uranium dioxide fuel pellets were replaced by a tungsten/uranium dioxide or tungsten/uranium nitride cermet and hydrogen flowed directly through the cermet. The cermet still would be contained within a cylindrical clad to ease fabrication and testing of the system, and the module geometry would be quite similar to that of the baseline system. The cermet fuel fraction in the HBS cermet core is higher than in other heatpipe-cooled cermet core designs, which reduces core size. Tungstenclad uranium carbide fuel pins also have been tested, with favorable results. The use of tungsten-clad uranium carbide would reduce the HBS core size and possibly allow a higher fuel power density.

\section{HPS AND HBS DEVELOPMENT}

HPS development will begin with a low-cost module test that uses electric heaters to simulate fission power. The test will demonstrate module fabricability, module heat transfer, module ability to withstand thermal stresses and thermal cycling, and the ability to couple power conversion systems (thermoelectric and AMTEC) to a $1275 \mathrm{~K}$ heatpipe. If the module test is successful, 12 modules will be brazed together into the reference core configuration, and the core will be used for electrical testing and zero-power critical testing. The braze between modules is not required, but it does reduce peak fuel temperature in the case of a failed heatpipe. Other methods for improving heat transfer (such as a refractory metal wool) also will be tested in this core. Information gained from the tests then will be used to design and fabricate the flight unit.

Existing facilities at the New Mexico Engineering Research Institute can be used to perform the module test (Mulder 1995), and the cost of module fabrication is estimated to be less than $\$ 100 \mathrm{k}$. Uranium nitride fuel fabricated during the SP-100 program is in storage at Los Alamos and can be resintered inexpensively for use in the HPS zeropower critical test and first flight unit (Chidester 1995). If desired, a full nuclear test of a module can be performed inexpensively in several countries (Batyrbekov 1995). The nuclear test of a module is not required but would increase user confidence. Because of the low HPS module power density, low enriched uranium would provide the desired module power in most test reactors, and highly enriched uranium would not be needed for the module test.

HBS development is similar, although the modules will be joined together at a common plenum and thus are not totally independent. Plenum design and fabrication will add to the development expense. Electrically heated tests also will include a helium flow test to ensure that the desired propellant exhaust temperature is attained. A detachable nozzle is desirable to allow the fuel to remain separate from the reactor until shortly before launch.

Another technical issue to be resolved is the sealing of the HPS uranium nitride fuel pin shortly before launch (if the uranium nitride option is chosen). One possible solution is to bond an end cap that contains a small tube to the end of the fuel pin. Because the end cap will have a direct view of space and will be several centimeters from the fueled region of the core, a low-temperature braze should be adequate for creating a seal between the end cap and the fuel pin. The fuel pin would be evacuated through the tube, back-filled with helium (if desired), and then the tube would be pinched off. This would avoid the necessity of having a specialized environmentally controlled facility at the launch site. Leak testing of all seals could be performed easily, and the exact sealing procedure would be inexpensive to develop. HPS concepts using uranium carbonitride or uranium dioxide fuel pins could be vented to space and would not require a leak-tight seal.

\section{SUMMARY AND FUTURE WORK}

A summary of five core designs is given in Table 1. The neutronic and shielding analyses were performed using the three-dimensional (3D) Monte Carlo particle transport code "MCNP" (Briesmeister 1993). The thermal hydraulic analyses were performed using a 3D code developed at Los Alamos (HBSHT). Additional information on the analyses that have been performed are given in a companion paper (Poston 1996). HPS-4UN is a rapid-development HPS option that uses existing electrical heaters (from the TOPAZ International Program) to reduce cost and development time. HPS-7DS is an HPS option suited for use outside of earth orbit. HPS-10UCN is a high-power HPS option suitable for use in earth orbit or beyond that uses uranium carbonitride fuel. HPS- $10 \mathrm{UO}_{2}$ is a highpower HPS option suitable for use in earth orbit or beyond that uses uranium dioxide. $\mathrm{HBS}-10 \mathrm{UO}_{2}$ is a potential HBS design. The estimated mass of a $5-\mathrm{kWe}$ thermoelectric power conversion system is $85 \mathrm{~kg}$. The estimated instrumentation and control system mass for the HPS (including actuators and an automatic controller) is $50 \mathrm{~kg}$ 
(Wyant 1995). As shown in Table 1, several HPS options have a total core, reflector, shield, heat transport, power conversion, and instrumentation and control system mass of about $500 \mathrm{~kg}$.

The maximum thermal power is based on a maximum HPS uranium nitride fuel temperature of $1600 \mathrm{~K}$, or a maximum clad temperature of $1800 \mathrm{~K}$ for the uranium dioxide and uranium carbonitride cases. Thermal bonding between modules is assumed to be by radiation only, by a helium bond, by a lithium bond, or by a braze. Refractory metal wool could also be used to provide additional thermal bonding. The failed heatpipe result assumes that the worst-case heatpipe failure has occurred for each respective design. The maximum thermal power shown in Table 1 also assumes that the power profile is flattened. HBS uranium dioxide fuel restructuring will result in an isothermal surface on the inside of the uranium dioxide, causing partial axial power flattening. HPS power flattening can be accomplished by tailoring the rhenium concentration and/or fuel enrichment throughout the reactor.

TABLE 1. Summary of Parameters for 4 HPS and 1 HBS Core Designs.

\begin{tabular}{|c|c|c|c|c|c|}
\hline Design Name & HPS-4UN & HPS-7DS & $\begin{array}{l}\text { HPS- } \\
\text { 10UCN }\end{array}$ & HPS-10UO 2 & HBS-10UO 2 \\
\hline $\begin{array}{l}\text { Number of Heatpipes (modules) } \\
\text { Number of Fuel Pins } \\
\text { Core Hex Flat to Flat }-\mathrm{cm} \\
\text { Active Core Height }-\mathrm{cm} \\
\text { Radref Thickness }-\mathrm{cm} \\
\text { Pin Outer Diameter }-\mathrm{cm} \\
\text { Pin } \mathrm{tD} \text { (Clad Thickness/Outer Diameter) }\end{array}$ & $\begin{array}{c}12 \\
48 \\
20.1 \\
31 \\
11 \\
2.54 \\
.050\end{array}$ & $\begin{array}{c}30 \\
138 \\
19.7 \\
32 \\
8 \\
1.50 \\
.050\end{array}$ & $\begin{array}{c}57 \\
270 \\
19.3 \\
33 \\
11 \\
1.05 \\
.050\end{array}$ & $\begin{array}{c}57 \\
270 \\
25.7 \\
36 \\
12 \\
1.40 \\
.050\end{array}$ & $\begin{array}{c}57 \\
270 \\
25.7 \\
42 \\
11 \\
1.40 \\
.050\end{array}$ \\
\hline $\begin{array}{l}\text { Fuel Material (93\% enriched) } \\
\text { Clad Material } \\
\text { Vessel / Slat Material } \\
\text { Interstitial Fill (55\% void) }\end{array}$ & $\begin{array}{l}96 \% \mathrm{TD} \text { UN } \\
\begin{array}{c}\mathrm{Nb} 1 \mathrm{Zr} / \mathrm{Re} \\
\mathrm{Mo} \\
\mathrm{Nb} 1 \% \mathrm{~B} 4 \mathrm{C}\end{array}\end{array}$ & $\begin{array}{c}96 \% \mathrm{TD} \mathrm{UN} \\
\mathrm{Nb1Zr/Re} \\
\mathrm{Mo} \\
\text { none }\end{array}$ & $\left|\begin{array}{c}13 \mathrm{~g} / \mathrm{cc} \mathrm{UCN} \\
\mathrm{Mo3Nb} \\
\mathrm{Mo} 3 \mathrm{Nb} \\
\mathrm{Mo} 10 \% \mathrm{~B} 4 \mathrm{C}\end{array}\right|$ & $\mid$\begin{tabular}{c|}
$85 \% \mathrm{TD}$ \\
$\mathrm{UO}_{2}$ \\
$\mathrm{Mo} 3 \mathrm{Nb}$ \\
$\mathrm{Mo} 3 \mathrm{Nb}$ \\
$\mathrm{Mo} 10 \% \mathrm{~B} 4 \mathrm{C}$
\end{tabular} & $\begin{array}{l}85 \% \mathrm{TD} \\
\mathrm{UO}_{2} \\
\mathrm{~W} \\
\text { Mo10Re } \\
\text { none }\end{array}$ \\
\hline $\begin{array}{l}\text { U-235 Loading - kg } \\
\text { Radref Mass - kg } \\
\text { Reactor Mass (inc. radref) - kg } \\
\text { Shield Mass @ 100kWt (dose req. in text) - kg } \\
\text { Mass (Core, Reflector, Shield, Heat Transport) }\end{array}$ & $\begin{array}{l}73 \\
114 \\
248 \\
110 \\
358\end{array}$ & $\begin{array}{l}77 \\
72 \\
199 \\
100 \\
299\end{array}$ & $\begin{array}{l}70 \\
122 \\
252 \\
110 \\
362\end{array}$ & $\begin{array}{c}94 \\
180 \\
372 \\
125 \\
497\end{array}$ & $\begin{array}{l}115 \\
171 \\
415 \\
125 \\
540\end{array}$ \\
\hline $\begin{array}{l}\text { k-eff, Drums Out, Beginning of life (BOL) } \\
\text { k-eff, Drums In, BOL } \\
\text { k-eff, Immersed, Drums In, BOL } \\
\text { k-eff, Immersed, Wet sand replace radref,BOL } \\
\text { k-eff, Immersed, H2O replace radref, BOL }\end{array}$ & $\begin{array}{l}1.030 \\
0.923 \\
0.982 \\
0.992 \\
0.940\end{array}$ & $\begin{array}{c}1.030 \\
0.890 \\
\text { dependent } \\
\text { on shutdown } \\
\text { mechanism }\end{array}$ & $\begin{array}{l}1.031 \\
0.919 \\
0.979 \\
0.986 \\
0.943\end{array}$ & $\begin{array}{l}1.030 \\
0.920 \\
0.990 \\
0.992 \\
0.943\end{array}$ & $\begin{array}{l}1.032 \\
0.923 \\
0.992 \\
0.990 \\
0.940\end{array}$ \\
\hline Peak Bumup/yr per $100 \mathrm{kWt}$ & $.072 \%$ & $.068 \%$ & $.075 \%$ & $.060 \%$ & $.048 \%$ \\
\hline Max HP radial heat flux per $100 \mathrm{kWt}-\mathrm{W} / \mathrm{cm}^{2}$ & 45 & 27 & 18 & 15 & 11 \\
\hline Max HP axial heat flux per $100 \mathrm{kWt}-\mathrm{kW} / \mathrm{cm}^{2}$ & 2.1 & 2.3 & 2.5 & 1.3 & 1.5 \\
\hline \multicolumn{6}{|c|}{ Maximum Thermal Power - $\mathrm{kWt}$ (nominal/failed heatpipe). For max UN=1600K or max UCN/UO 2 clad $=1800 \mathrm{~K}$} \\
\hline $\begin{array}{l}10 \text { deg. solid conduction between modules } \\
\text { Radiation only between modules }(e=.5) \\
\text { Helium Interstitial Fill } \\
\text { Lithium Interstitial Fill }\end{array}$ & \begin{tabular}{|c|}
$180 / 75$ \\
$160 / 50$ \\
$160 / 60$ \\
$200 / 100$ \\
\end{tabular} & $\begin{array}{l}360 / 150 \\
330 / 75 \\
330 / 125 \\
410 / 210 \\
\end{array}$ & \begin{tabular}{l|}
$1400 / 555$ \\
$1200 / 250$ \\
$1200 / 430$ \\
$1500 / 820$ \\
\end{tabular} & \begin{tabular}{|l|}
$1200 / 460$ \\
$1000 / 300$ \\
$1000 / 370$ \\
$1300 / 640$ \\
\end{tabular} & $\begin{array}{c}125 / 110 \\
120 / 95 \\
\text { N/A } \\
\text { N/A } \\
\end{array}$ \\
\hline
\end{tabular}

Flattening also can be achieved in the HPS by placing material in the interstitials; this also will reduce system mass by reducing the void space and thus reducing the amount of resonance-absorbing material needed to ensure launch accident subcriticality. If no attempt is made to flatten the power profile, the maximum power drops by $\sim 20 \%$ because of peaking. Preliminary calculations indicate that power flattening will result in zero or minimal mass and volume penalties. HBS- $10 \mathrm{UO}_{2}$ is designed to produce $\sim 100 \mathrm{kWt}$ in the power-only mode. The addition of thermal 
bonding between the heatpipes and the cylinders surrounding them would add some complexity to the module design but could greatly increase the power production capability in the power-only mode.

Although additional HPS and HBS design work is needed, the most important near-term development step is testing of the electrically heated HPS module. The module test will demonstrate most key issues associated with HPS development.

\section{CONCLUSIONS}

Two inexpensive, near-term space fission power concepts (HPS and HBS) are proposed in this paper. Both concepts have 10 important features:

1. Only existing technology and recently tested fuel forms are used.

2. Fuel can be removed whenever desired, which greatly facilitates system fabrication and handling.

3. Full electrically heated system testing of all modes is possible, with minimal operations required to replace the heaters with fuel and to ready the system for launch.

4. The systems are passively subcritical during launch accidents.

5. A modular approach is used, and most technical issues can be resolved with inexpensive module tests.

6. Bonds between dissimilar metals are minimized.

7. There are no single-point failures during power mode operation.

8. The fuel burnup rate is quite low to help ensure $>10$-yr system life.

9. There are no pumped coolant loops, and the systems can be shut down and restarted without coolant freeze/thaw concerns.

10. A full ground nuclear test is not needed, and development costs will be low.

\section{Acknowledgments}

The authors wish to thank the numerous individuals within the space power community who have contributed comments and suggestions related to the HPS and the HBS concepts. The designs have benefited greatly from this input.

\section{References}

Batyrbekov, G.A., personal communication, National Nuclear Center, Semipalatinsk, Republic of Kazakhstan, March 1995.

Briesmeister, J.F., "MCNP-A General Monte Carlo N-Particle Transport Code," Los Alamos National Laboratory report LA-12625-M (1993).

Chidester, K., Los Alamos National Laboratory, personal communication (March 1995).

Houts, M.G., L.L. Begg, W.R. Wharton, and L.A. Lawrence, "Technical Accomplishments of the Thermionic Fuel Element Verification Program," in Proceedings of the $11^{\text {th }}$ Symposium on Space Nuclear Power and Propulsion, DOE CONF-940101, M.S. El-Genk ed., University of New Mexico's ISNPS, Albuquerque, New Mexico: 9971008 (1994). 
Izhvanov, O.L., New Mexico Engineering Research Institute, Albuquerque, NM, personal communication (March 1995).

Makenas, B.J., D.M. Paxton, S. Vaidyanathan, and C.W. Hoth, "SP-100 Fuel Pin Performance: Results from Irradiation Testing," in Proceedings of the $11^{\text {th }}$ Symposium on Space Nuclear Power and Propulsion, DOE CONF-940101, M.S. El-Genk ed., University of New Mexico's ISNPS, Albuquerque, New Mexico: 403-412 (1994).

Matthews, R.B., R.E. Baars, H.T. Blair, D.P. Butt, R.E. Mason, W.A. Stark, E.K. Storms, and T.C. Wallace, "Fuels for Space Nuclear Power and Propulsion: 1983-1993," in A Critical Review of Space Nuclear Power and Propulsion 1984-1993, M.S. El-Genk ed., American Institute of Physics (1994).

Mulder, D., New Mexico Engineering Research Institute, personal communication (March 1995).

Poston, D.I. and M.G. Houts (1996), "Nuclear and Thermal Analysis of the Heatpipe Power and Bimodal Systems," in Proceedings of the $13^{\text {th }}$ Symposium on Space Nuclear Power and Propulsion, CONF-960109, M.S. El-Genk ed., American Institute of Physics, New York, AIP Conf. Proc. No. TBD.

Raag, V., Thermotrex, Waltham, MA, personal communication (August 1995).

Ranken, W.A., P.J. Drivas, and V. Raag, "Low Risk Low Power Heat Pipe/Thermoelectric Space Power Supply," in Proceedings of the $7^{\text {th }}$ Symposium on Space Nuclear Power and Propulsion, M.S. El-Genk ed., University of New Mexico's ISNPS, Albuquerque, New Mexico: 488-496 (1990).

Wold, S., O. L. Izhvanov, V. I. Vibivanets, and G. L. Schmidt, "TOPAZ-II Thermionic Fuel Element Testing," in Proceedings of the $11^{\text {th }}$ Symposium on Space Nuclear Power and Propulsion, DOE CONF-940101, M.S. ElGenk ed., University of New Mexico's ISNPS, Albuquerque, New Mexico: 1025-1030 (1994).

Wyant, F., New Mexico Engineering Research Institute, personal communication (October 1995). 


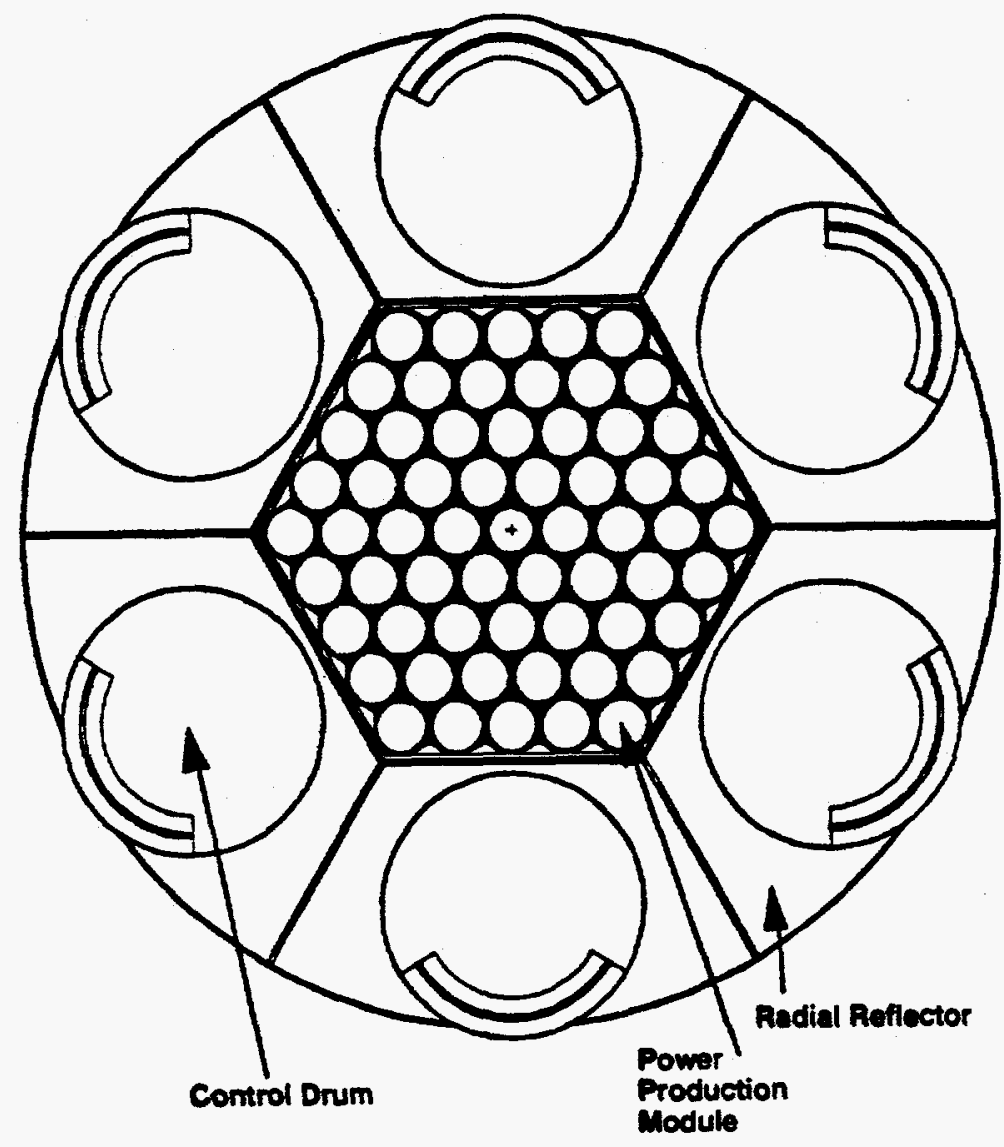

FIGURE 1. Schematic of HPS Showing Fuel Pins and Radial Reflector.

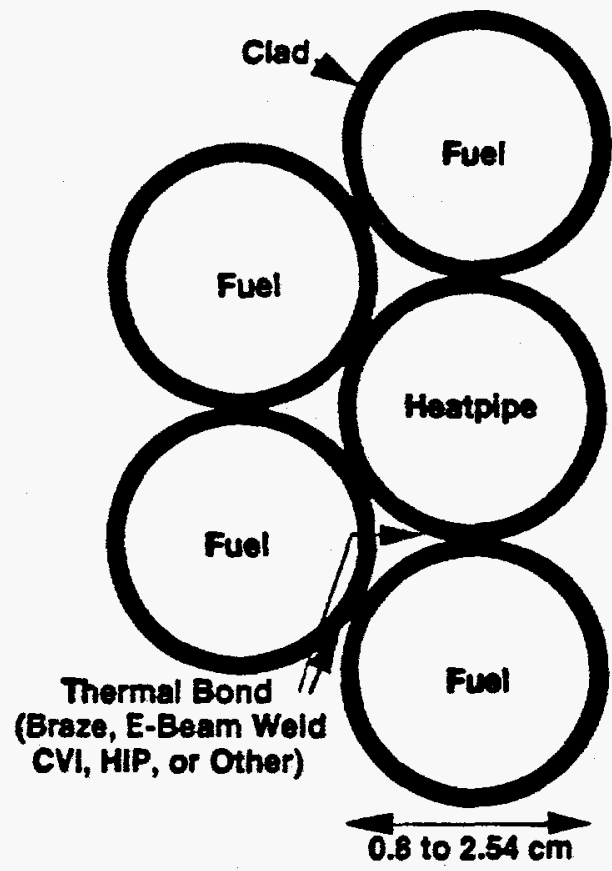

FIGURE 2. Schematic of HPS Power Module.

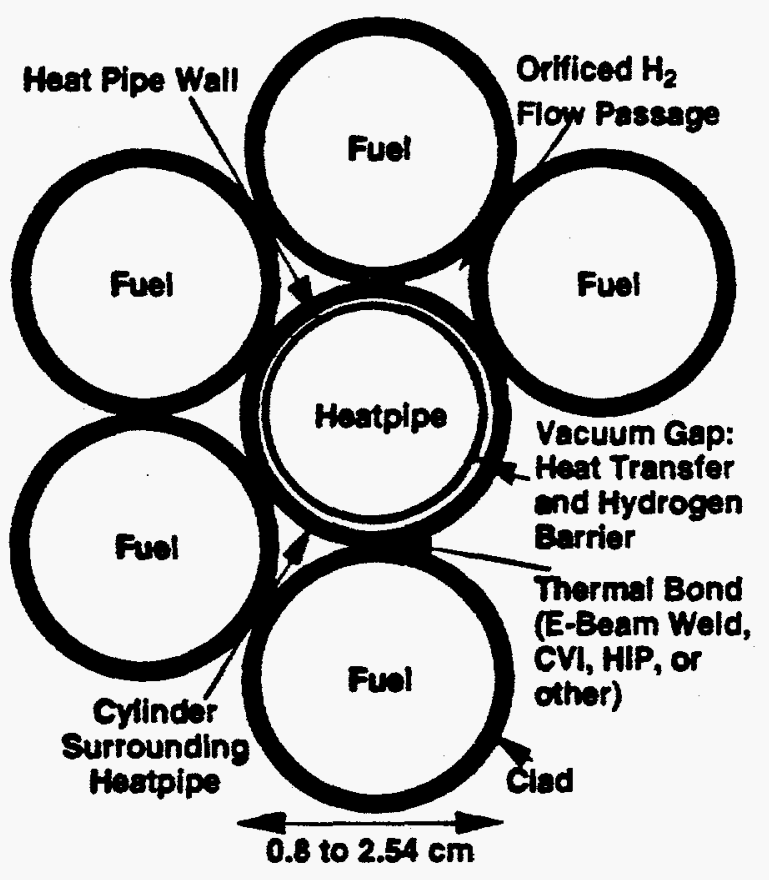

FIGURE 3. Schematic of HBS Power / Propulsion Module. 